\title{
Socio-Cultural Aspects of Solid Waste Crisis in Sri Lanka
}

\author{
MTM Mahees \\ Department of Sociology, Faculty of Arts, University of Colombo
}

\begin{abstract}
The contemporary societies are facing various environmental issues and challenges due to massive development projects, changing consumption pattern and environmentally harmful attitude. The present human culture continues to dominate and conquer all aspects of nature in an alarming manner. As a result, the so called modern or postmodern man has to experience the extreme climate change, natural disasters, loss of biodiversity, human-wild life conflicts, waste crisis and environmental poverty. The waste crisis (generation, health risk, management and its politics) is one of the leading and threatening socio-environmental problem to Sri Lanka. It is important to understand the hidden and subjective cause of solid waste crisis of Sri Lanka through sociological analysis of socio-cultural factors. The main objective of this paper is to analysis the social and cultural aspects of solid waste generation and disposal in Sri Lanka. The paper is based on the study carried out in four DS divisions of Kandy District and existing secondary data and related literature. The quantitative and qualitative data were collected from shopowners $(n=150)$ and households $(n=200)$ through 350 questionnaire survey and 30 in-depth interviews. This paper has focused more on the qualitative aspects of solid waste crisis of Sri Lankan by exploring the underlining socio-cultural causes of the crisis. The symbolic consumption pattern and its impact on rapid waste generation, higher degree of food waste and development of throwaway society, the cultural notion of dirt and its link with solid waste issue, social class and waste management, socio-ethnic belief and practices and gender aspects of waste generation and disposal are the key sociological factors that found be determining the solid waste crisis of Sri Lanka.
\end{abstract}

Key Words: Solid Waste, Social Environment, Gender relationship, Socio Ethics 


\section{Introduction}

The solid waste crisis is not a mere environmental problem but social problem too. Although solid waste crisis is mostly based on socio-economic, cultural and political aspects, the relevant field is still under the influence of engineering and technical discourse and solutions in Sri Lanka. Sociology and environmental sociology can play a leading role in understanding the underlining and subjective facets of the solid waste crisis in contemporary Sri Lanka. From generation to sustainable solid waste management needs to be addressed through the factors such as attitude, consumption, life style, notion of purity and gender relation which are broadly analyzed in the discipline of sociology. Thus, anthropologists and sociologists are more concerned about cause and pattern of waste generation more than solid waste management process.

The main objective of this paper is to analyse the social and cultural aspects of solid waste generation and its impact on solid waste management. This paper attempts to explore the relationship between factors such as social class, cultural values, notion of pollution and consumption with solid waste generation and management by using secondary data and field data collected in four divisional secretariats in Kandy District. The primary field data were collected from the exploratory study carried out at four Divisional secretariats of Kandy district, Harispattuwa, Akurana, Pujapitiya and Pathadumbara. The observation, questionnaire survey and in-depth interviews were used as major data collection tools. For this purpose, 350 questionnaires were administrated on households (200) and shops (150) located in four Divisional Secretaries based on simple random sampling method. The questionnaire survey was aimed to gather socio-economic, family and attitudinal information related to waste generation and 
management. Thirty (30) in-depth interviews were used to collect more qualitative on the basis of purposive sample method. The existing knowledge and information on solid waste generation and management were reviewed from sociological perspectives. The data were quantitatively and qualitatively analysed.

The solid waste is becoming a major problem in the developing countries though the countries still generate much less than developed countries when per capita figures are compared. According to the feasibility study report for Municipal solid waste disposal (2017), the per capita solid waste generation (kg/day) of selected world cities are New York (1.8), Singapore (0.87), Colombo (0.85), Rome (0.69), Jakarta (0.60), Manila (0.50) and Calcutta (0.50). It is also important to note the different level of per capita generation of solid waste (kg/day) in Sri Lankan local authorities, Municipal Councils (0.60), Urban Councils (0.60) and Pradeshiya Sabas / Village Council (0.40). Sri Lankans generate approximately $0.62 \mathrm{~kg}$ of solid waste per day on average. The total solid waste generation of Sri Lanka is from 8000 to 15000 metric tons per day and average garbage production is around 4.5 million metric tons per year. However, it is only around $40 \%$ solid wastes collected by local authorities from the average production of 12400 metric tons per day (Bandara, 2008).

According to National Policy on solid waste management, there are three categories of solid waste in Sri Lanka, they are municipal solid waste, health care solid waste and hazardous solid waste. A proper analyzing of composition of solid waste is very important to critically understand the nature of solid waste generation and confront the challenges of sustainable solid waste management. The present and average categories of municipal solid waste is bio-degradable waste (short term) $68.4 \%$, bio-degradable 
waste (long term) $2.5 \%$, polythene/plastic waste/ shopping bags $9.2 \%$ metal waste $0.9 \%$, wooden waste $3.5 \%$, glass waste $4.1 \%$, paper waste $6.6 \%$ and other waste 5\% (NSWMSC, 2010). The moisture content of municipal solid waste is also very high in the range of $70-80 \%$ on a wet weight basis. Primary components on a weight basis are compostable organics; food and garden waste accounting for 89.2\% (Gunaruwan \& Gunasekara, 2016). According to these statistics, more than $60 \%$ of solid waste is food waste and culture of consuming food and life style of Sri Lankans could be critically analysed by food waste. Solid waste is closely related to market economy and class structure of a society. Who generate waste and who suffer by those waste and discrimination in waste management are based on the socioeconomic and cultural aspects of solid waste generation and management.

Although there are many solid waste management systems such as composting, recycling, land filling, open dumping, incineration and energy recovery in the global level, Sri Lanka as a developing country mostly follows land open dumping method and minor level composting strategy too. The open dumping practice causes many socio-economic and institutional problems due to poor infrastructure facilities. In the meantime, Sri Lanka is attempting to go for land fill strategy with the support of technical and engineering advice related to this method (Werellagama, 2000). Solid waste is a growing problem in Sri Lanka aggravated by the absence of proper management systems. Development and implementation of a national strategy for solid waste management in Sri Lanka is essential to reduce environmental, social and economic problems associated with the present disposal practices.

It is clear that there is a huge gap between solid waste generation (average generation is 12500 metric tons per day) and proper solid waste management 
(only $40 \%$ or 5000 metric tons are managed) in Sri Lanka. The unmanageable or uncollected solid waste has been creating many sociocultural and political problems in Sri Lanka. Sometimes this amount of waste is improperly dumped or illegally disposed and left alone causing many crises in society and among the institutions. Today waste management has become the core business of local authorities of Sri Lanka and the Municipal and Urban councils spend their larger portion of fund towards the waste management. The solid waste crisis and its related issues such as spread of dengue epidemics have politically challenged the existence of government and creating many contradictions among the state bodies (central, provincial and local). The recent disaster of Meethotamulla incident is a very good example for politicization of solid waste management in Sri Lanka.

The definition of waste can be very subjective; what represents waste to one person may be valuable to another. However, waste must have firm legal definition. There are many different terms to describe the diverse types of waste including "controlled, household, industrial, commercial, special, active and inactive". In such cases, firm definitions of waste have financial and legal implication for business, local authorities and government.

According to McDougall et al. (2001), waste can be categorized by a magnitude of schemes, by physical state (solid, liquid, gaseous), and within solid waste by original use (packaging waste, food waste, etc.), by material (glass, paper, etc.), by physical properties (combustible, compostable, recyclable), by origin (domestic, commercial, agricultural, industrial, etc.) or by safety level (hazardous, non-hazardous). The household and commercial solid waste are often referred to be Municipal Solid Waste. 
The legal definition of a solid waste is not based on the physical form of the material, but on the fact that material is a waste. Thus, solid waste are defined as " any garbage, refuse, sludge from a wastewater treatment plant, water supply treatment plant, or oil pollution control facility, and other discarded material, including, solid, liquid, semisolid, or contain gaseous material, resulting from industrial, commercial, mining, and agricultural operations and from community activities (Environmental Protection Agency, 2001).

\section{Social aspects of waste}

Waste is very much related with our day to-day life. It is possible to understand the social life of people through the cross-cutting of waste generation. John Scanlan, in his influential book 'On Garbage', has examined the role of the idea of waste in making of modernity. In particularly, he has identified the material and intellectual productions of waste as a product of enlightenment conceptions of efficiency, productivity, and "right use" a moral economy of waste that lies at the heart of modernity. Scanlan (2005) shows that waste has been a central category in the operation of modernity, where the useful is constantly (re)valorized by its distinction from the useless. He places waste at the heart of the ideological operation of modernity, as the means by which value is both produced and contested.

Another crucial insight comes from the work of Zsuzsa Gille (2007) who wrote 'From the Cult of Waste to the Trash Heap of History' has developed a "sociology of waste" that suggests the possibility of a systematic study of the relations between the material reality of waste and its socio-cultural construction. Gille has theorized the existence of "waste regimes," particular modes of valorizing waste and of disciplining subjects in relation to waste. 
For Gille, waste is as much a social process as a material object, a process in which social relations determine how waste acquires or loses value.

The present society mostly depends on the consumption rather than production, whether it is production based or consumer based society, waste is the final outcome of both process. Societies produce more waste than goods and $98 \%$ of the original materials used in the production of, or contained within, the goods made in the USA become waste within six weeks of sale (Hawken, 1994). The social factors such as life style, neighborhood, social class and family size have played crucial role in determining solid waste generation of this study. According to Guan et al. (2002), the changing life style through consumption pattern in the developing countries causes many environmental issues such as waste generation. Life style is having close correlation with waste generation, the life style of food practice (dining out and home cooking) is found significant in generating waste (Mahees et al, 2011). According to the respondents' views relationship between life style and solid waste generation are strongly related. The life style mainly includes consumption, entertainment and social gathering of people. The Table No 1 presents the views of both households and shop-owners in this regard.

Table 1 Life style and solid waste generation are related

\begin{tabular}{lcc}
\hline Response & Households (\%) & Shop-owners (\%) \\
\hline Agree & $136(63)$ & $70(47)$ \\
Neutral & $35(17)$ & $53(35)$ \\
Disagree & $39(20)$ & $27(18)$ \\
\hline Total & $200(100)$ & $150(100)$ \\
\hline
\end{tabular}

Source: Field Data, 2010 
According to above Table, 63\% households and 47\% of shop-owners agreed that life style is related to solid waste generation. Only $20 \%$ of households disagreed with this statement and majority of shop-owners (53\%) had either neutral or disagreement with the statement of 'life style is related to solid waste generation'. On the other hand, if the 'neutral' opinion of shop-owners is calculated into disagreement, there could be less or no different between household and shop-owners in this regard. However, in general the degree of agreement of households is higher than the shop-owners in terms of solid waste generation is related to life style. The difference between households and shop-owners in terms of life style and solid waste generation are related is found significant $(\mathrm{p}=0.002)$ with the Chi Square value of 19.41. Households feel this relationship subjectively whereas shop-owners get it mostly in an objective manner. Consumption of excessive foods (fruits, vegetable, packed or bottled items), preference of offering meal for others, purchasing of reading materials, unban neighborhood and competition of following modern life style are the foundations for the positive link between life style and solid waste generation.

The social aspect in terms of waste generation and disposal is one of the most important sociological factors emphasizing the subjective and underlining characteristics of this environmental crisis. Waste is a social reality and different according to societies and represents a cultural and social value for individuals in the society. The concept of "throwaway society' is very useful in understanding the solid waste crisis in the present world including the waste problem of Sri Lanka. When a society is influenced by over or unnecessary consumption and producing more garbage, it is a kind of throwaway society. The basic meaning of throwaway society is that people consume more and more goods and use them for little period and throw them away without using them for a longer period or 
society does not have any social value of reusing those things. People in the contemporary society always prefer to buy symbols or signs more than goods and services. The present consumers are more concerned about sign value more than the use or exchange value. The many of consumer products that are found in super markets or shopping malls are well and attractively packed with polythene, plastic, cardboard or any other hard materials. These symbolic consumptions always end up in waste because of throwaway society. One can clearly observe it when he or she looks at a garbage site anywhere in a town or city in Sri Lanka. It is further proved by the study of Mahees et al, (2011) concluding that the family size and food consumption of urban community always positively correlated with solid waste generation in Sri Lanka.

According to Martin O'Brien (1999) discourses surrounding pre-packed food products highlighted the relations between the material nature of waste and the changing character of modern capitalist production. Packaging was presented by industry as a desirable innovation that was both modern and hygienic. But packaging was also an essential factor in overcoming the established taboos of a hygiene-obsessed society, an obsession which made the development and spread of the supermarket distribution system possible.

According to Beall (2006), in South Asia, social relations intersect with the management of waste in a very particular way. All over the world, waste workers are stigmatized and are likely to be from marginalized groups such as ethnic or religious minorities or rural migrants. The low social status of people dealing with rubbish is compounded in South Asia by association of this work with caste. It is a socially marginalized group who mainly represent the waste collecting community in Sri Lanka including the study area and they have been experiencing various socio-cultural issues and 
challenges due to their marginalized position in SWM hierarchy. For example, some shop-owners are not interested in selling or serving foods to waste collectors at their hotels. The term used to call waste pickers in Sri Lanka is demeaning and discriminating socially and culturally. Even the term "scavenger" used by English speakers cause severe damage to people who are engaged as waste collectors. The lower social dignity and poor facilities offered to waste collectors and health and sanitary related problems encountered by these workers always discouraged their proper and active involvement in SWM in the study area. Moreover, although the majority (65\% Muslims and rest is Sinhalese) of people in the study area are Muslims, there is not even a single person involved in SWM process done by local government authority. Only very few low socio-economically marginalized Sinhalese and Tamils belonging to plantation community and low caste groups are engaged in these sanitary related works. The zero representation of Muslims in the SWM community always created wrong picture about the waste collectors in study area. However, there are considerable numbers of Muslim sanitary workers involved at SWM process in many other Muslim majority local authority areas such as Kalmunai, Sammanthurai and Akkaraiapattu.

According to Ulrich Beck and Elisabeth Beck (2005), the institutionalized individualization with influence of globalization and changing economic power has eradicated collective responsibilities, social rights and cohesion. The middle class which constitutes a sizeable percentage of India's population, and their behaviors have a significant impact on environment. Wealthier groups in India, especially in urban areas, make higher demands upon environmental goods and capacities through their ability to command more resources such as per capita water and electricity, consumer products and their greater waste production, including vehicle emission and garbage 
(Buck, 1993 and Panch, 1993). This type of individualization could be observed from rich class of the study area that has very poor concern on collective responsibilities in terms of environmental behavior. According to in-depth interview (Conducted in four Kandy DS divisions) findings, two types of purity practices are found among the middle and upper middle class business community of study area depending on their cultural notion of dirt and clean.

1 Private purity

2 Public purity

Here the private purity refers to individualized attitude and practices in terms of sanitation and removal of individual waste out of their household or shop's premises without any concern over outer environment. People who are concerned only about their individual (domestic or commercial) environment or private purity always dispose their solid waste wherever they can dispose out of their premises. The similar behavior could be observed even in Colombo metropolitan areas where some people are only concerned about their individual purity and throw the waste in common or public places. They always consider that their waste should not be in their back yard which is known as NIMBY (not in my back yard). The illegal or unethical disposal of waste into public places by households or shop owners in Colombo and some other cities is a serious moral issue in term of environmental attitude and behavior of people. Sociologists must earnestly think about the collective environmental sentiments of city dwellers in terms of waste disposal. Today from time to time, solid waste dumps are seen everywhere in Colombo is matter of collective conscience of people and urban governance of Sri Lanka. 


\section{The notion of dirt and solid waste}

Where do Sri Lankans build their toilet? Is it inside the house or outside the house or else at the corner of their garden? And where do they keep the food waste until they dispose? All these depend on the notion of dirt or pollution. Even in the modern society, some people do not like to use water closet (commodes) toilet due to the fact that personal or cultural notion of dirt. Another example is that cleaning and preparing a dead body for the final ritual could be usually performed by undertakers but in Muslim community it is done by close relatives. While it could be a cultural pollution to one community, it is a compulsory ritual service for another community. Thus, solid waste generation and disposal are also linked with the concept of dirt and it is very much cultured behavior.

Anthropologists have been very much interested in pure (sacred) and impure (profane) regarding food, hygiene, sexuality and other social behavior. The idea of pollution is supposed to be operating as a response to violation of social and cultural boundaries in two ways. First, characterizing something as pollution seeks to influence the behavior of others, and second, the label of pollution can defend general views of the social order (Nagle, 2009). However, present anthropologists and sociologists attempt to use the 'idea of pollution' developed by early anthropologists to define even the environmental pollution.

Pollution has always had dual meanings: a broad reference to all sorts of effects upon human environments, and a narrow focus upon natural environments. In fact, until less than a century ago society applied the term to human environments more often than natural environments. Mary Douglas was one of the most important writers to explore the concept of pollution in 
the twentieth century. Douglas considered the nature of pollution ideas in the context of traditional native cultures based on ritual cleanness.

The classic study on the notion of pollution is found in Douglas's Purity and Danger: An Analysis of Concepts of Pollution and Taboo (1966). Marry Douglas and Aaron Wildavsky elaborated these views sixteen years later in Risk and Culture (1982), which investigated "the sudden, widespread, across-the-board concern about environmental pollution and personal contamination that has arisen in the Western world in general and with particular force in the United States. Douglas and Wildavsky identified two senses in which people employ the term pollution: a technical sense of typical of air and water pollution "when the physical adulteration of an earlier state can be precisely measured and a nontechnical sense connoting moral defect in which "pollution is a contagious state, harmful, caused by outside intervention, but mysterious in its origin. These latter pollution beliefs "uphold conceptual categories dividing the moral from the immoral and so sustain the vision of the good society.

"Dirt implies two conditions: a set of ordered relations and a contravention of that order. Then, dirt is never a unique or isolated event. Where there is dirt there is system. Dirt is by-product of a systematic ordering and classification of matter, in so far as ordering involves rejecting inappropriate elements. It is obvious what is clean and dirt depends on a system of classification and the location of that matter within that system (Wuthnow et al., 1984).

According to Marry Douglas (1966) and Beall (2006) what makes things dirt or clean is based on the moral order of a society which periodically renews and reaffirms its basic relations and collective sentiments. Dirt is always socially constructed, cultural and relative. The attitude towards dirt and clean 
depends on the factors such as age, gender, education level, religious background and neighborhood. For example, the pollution towards the pork and beef is very much religious and cultural which could affect even the waste discourse.

The elderly people who live in a congested neighborhood have poor preference of storing or composting solid waste within their premises due to cultural notion of dirt. As a result, some elderly persons are not interested in even having a toilet inside their house. This cultural notion of dirt affects the solid waste generation at houses and shops. Also, it is important to understand the gender and ethnic perceptions with regard to cultural notion of waste. For example, some women do not prefer to keep a composting bin inside their house (premises) because of worms and flies found in the composting bin. Sometimes these women have tended to pour kerosene or put some chemical to their composting bin in order to control these worms without knowing proper function of them. However, the cultural notion of middle class people has changed positively with the impact of increasing female education and economic development. Thus, it is very significant to have subjective and broader understanding of notion of dirt and clean of a community to introduce or implement any of the SWM strategies. Unfortunately, nowhere in Sri Lanka, the notion of dirt of respective community or social groups is taken into account in the process of developing and practicing a SWM plan.

\section{Culture and solid waste}

The term culture basically refers to commonly accepted pattern of behavior that includes language, symbols, belief, customs, values, norms, sanctions, skills, capabilities and all material thing produced by man. The cultural construction of social realities or environmental health issues is another 
significant cultural aspect of this study. According to Peter Berger (1966), the reality or knowledge is socially (culturally) constructed. He further states that 'sociology of knowledge will have to deal not only with the empirical variety of knowledge in human societies, but also with processes by which any such knowledge comes to be socially established as reality'.

The socially constructed perception of people regarding solid waste disposal and their impact on health issues is found significant in this study. The perception of average people and their local knowledge have to be taken into consideration equal to scientific discourses. However, these local knowledge or culturally constructed realities cannot be proved on statistical or quantitative ground, but need to be understood subjectively and qualitatively. Since culturally constructed social realities are more powerful than scientific realities, it was very difficult to make people understand the negative impact of solid waste disposal. The long-established beliefs and cultural values related to environment is very vital to understand the solid waste crisis. Some believe that some environmental health diseases such as diarrhea, hepatitis and dengue fever break out due to divine wrath, not because of environmental pollution. At the same time, they believe that nature is creation of God and polluting nature (environment) is almost like bringing contempt before the God. For example, when it is found difficult to control dumping garbage besides the roads or in public places in urban area of Sri Lanka, people temporarily keep statues of god or Buddha close-by those dumping sites in order to prevent improper waste disposal. However, according to the in-depth interview findings, there are three major cultural factors that influence the solid waste disposal practice of people. These three factors as part of everyday life functioned as a cultural circle that determine to influence the generation and disposal practice of waste. It was a cultural model developed through this study which is presented as follows by the 
Figure 1. Cultural Circle of Waste Disposal

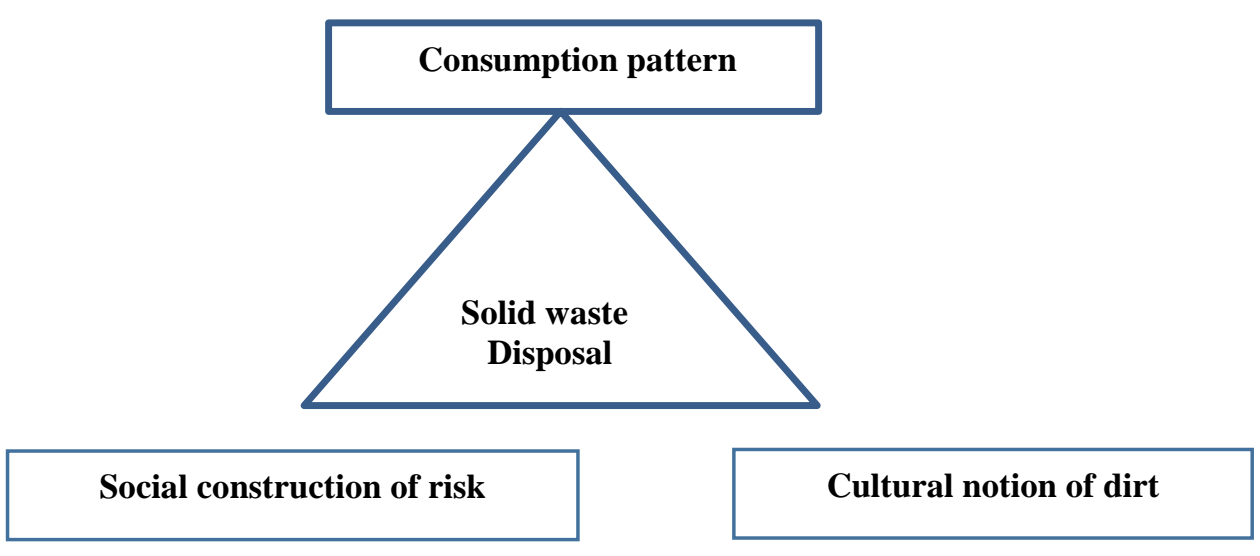

Ethnicity and race are two important concepts determining environmental concern and attitude. The socio-cultural and political functions of these two factors are almost equal to each other. Race is a kind of unique cultural pattern or behavioral type based on physical characteristics, eg African American culture (Black) and Anglo American culture (White). The concept of ethnicity which mainly functions in Sri Lanka instead of race is cultural not biological. Ethnicity is a distinct cultural tradition shared by a group of people who identify themselves on the basis of commonality such as religion, ethnic origin, language and other cultural practices. The ethnic background of a person largely affects his or her neighborhood arrangement, consumption patterns, eating habits, group enjoyment and socio-cultural functions (wedding, funeral and puberty ceremonies). For example, the food habit and entertaining family functions of one ethnic group is rather different from another ethnic group. And cultural festival such as Kandy Perahara, Fasting period of Muslims and Christmas cause to generate different nature of solid waste in different amount in different areas. In a broader context, 
the ethnicity of a person influences his or her environmental attitude in terms of generation and disposal of waste.

According to Morrissery and Manning (2000), there is a close relationship of race and ethnicity with environmental attitude. Many studies of black and white differences in environmental concern have often found race to be a significant predictor of attitude towards environmental issues (Tylor, 1989). For example, a survey in a metropolitan Virginia area found African American to be less environmentally concerned than Anglo Americans (Caron and Sheppard, 1995). However, in another sociological study of Caron (1989), he states that black and white do not significantly differ on their level of environmental concern.

According to Mahees \& Silva (2011), ethnicity is found significant in determining environmental attitude of respondents about solid waste generation and waste disposal. The relationship between ethnicity and environmental attitude of shop-owners is positively correlated in the study done in Kandy and they further pointed out that Sinhala shop-owners are more concerned about the environmental issues of solid waste than Muslim shop-owners. However, it is not general situation throughout the country.

The high price for business premises and extremely competitive business environment made these Muslim shop-owners more business oriented through rational profit maximization process. They often attempt to take the maximum utility of business lands because of limited land resources. Sinhala shop owners have been having close connection with physical environment compared to Muslim shop-owners. These respondents are interested in environmental issues and are concerned about environmentalism due to their positive awareness towards the environmental crises. 
It could be possible to witness different composition and amount of waste generation and disposal even in Colombo city depending on the different socio-ethnic neighborhood. The social security and religious cohesion based on rituals has always promoted ethnically made population or housing density in Colombo. It has indirectly aggravated the crisis of solid waste disposal. However, the impact of ethnicity on the solid waste crisis must be further analysed through a separate qualitative study.

\section{Gender relationship and waste}

Term gender basically refers to social and cultural differences between man and woman. This difference is socially constructed and functioned on different level of cultural and political power. Everything in the human society is influenced by the gender relationship and gender difference is not a problem only to women but also challenge and issue to me in the day today life. Even the waste is classified or identified based on the gender factor. For example, in normal gender based society, a used tire may be resource for a man whereas it could be a waste for woman on the other hand; ragged cloth may be recourse for woman and waste for a man.

The gender relationship of any particular society is another crucial cultural factor that can have huge impact on environmental attitude and action. Since women maintain closer relationship with environment (Sirisena, 2010) and women can function as an agent of social change in terms of environmental issues (Mahees et al., 2008), women are expected to control solid waste generation of domestic sources. Even this study reveals that women can have a control over the generation of SW. It could be witnessed by Table 2 . 
Table 2 : Women control waste generation

\begin{tabular}{lc}
\hline Response & Total $(\%)$ \\
\hline Strongly agree & $105(52)$ \\
Agree & $79(40)$ \\
Neutral & $9(4)$ \\
Disagree & $7(4)$ \\
\hline Total & $200(100)$ \\
\hline
\end{tabular}

Source: Field Data, 2010

According to Table 2, 52\% of the respondents of household questionnaire survey strongly agree that women can control domestic solid waste generation and another $40 \%$ of respondents agree with this statement. In general, $92 \%$ of the respondents are of the view that women can control SW within their household premises and it is only $7 \%$ of households who disagree with this statement. Women as domestic managers, main determiner of food consumption and leading socializing person of children can have manageable control over generation and management of SW with the support of men in any cultural context.

Women have the capacity of controlling solid waste generation by the three steps that could be practiced within household. They are (1) cutting off unnecessary consumption being economically rational (2) adapting or promoting environmentally friendly behavior through socialization process (3) improving technical knowledge in order to implement practical SWM system. Thus, according to these three dimensions, women can control consumption pattern through rational and economical purchasing of food, technological management of available food and changing of behavior related to over-consumption. However, though gender is crucial in solid waste management process, it should not be misinterpreted that women 
should be responsible for minimizing and managing solid waste at domestic level.

Gender relationship also plays a crucial role in SWM process. Women or widows who are under the urban poverty in many developing Asian countries make their means of living out of waste and even in Muslim countries such as Indonesia, Muslim women may not feel free to pick waste in public places but are likely to do the work of sorting, cleaning and packing waste (Fatimah, 1982). Many the street and dump pickers are women and children but the traders and managers of waste recycling industries are men in many developing countries (Furedy, 1990). Even in Sri Lanka women who work in the local authorities and other private environmental service companies are highly disadvantaged, they are generally paid less and treated unequally compared to men. According to Sakurai (1986), women waste pickers or street cleaners in Latin America and Asia are not having an opportunity of social mobility and usually subject to sexual abuse. However, according to study of gender perspective in community participation solid waste management by Vineeshiya \& Mahees (2016), the role of women has been very much successful proper community participation solid waste management at all level.

It is also worth mentioning that people are fighting as social or environmental movements specially in the developing world against the development projects or some environmental problems. In most of these grass roots collective environmental actions or environmentalism women are the leading actors and as a result, these movements are known as ecofeminism. (Mahees, 2010). At present, most of the waste disposal projects violate fundamental rights of the economically and politically powerless people, they have become the victim of modern solid waste management 
projects. Thus, new grassroots level and female lead movements are emerging against the nuclear waste, large scale industrial waste disposal, hazardous clinical waste disposal and illegal or unethical waste transportation. Even in Sri Lanka, there were lot of social protest against Gohagoda (Kandy), Bluemendal, and Meethotamulla dumping sites and some projects (Dompe, Meepe \& Aruwakkado/ Puttlam) are under the influence of public protest mainly lead by women and politically motivated men. It is thus obvious that women can play crucial role in minimizing solid waste generation, educating the community against waste crisis and promoting sustainable end environmentally sensitive waste management project.

\section{Conclusion}

Solid waste generation and sustainable waste management is a threatening problem to Sri Lanka. This crisis needs to be understood and solved on an interdisciplinary platform and sociological involvement is very much crucial in this regard. The political economy and its impact on changing pattern of society totally influence the waste generation pattern. The consumer culture which promotes symbolic consumption under the modern or postmodern social conditions is directly related to the crisis. The hyper-reality which is based artificial desires more than the real needs of people promote the consumer culture and leading to a throwaway society. This is obviously indicated by the $60 \%$ of food waste and re-usable material found in the waste. The waste generated by one social class may be the want for another social layer or livelihood for many others. On the other hand, the social class based solid waste crisis has been creating environmental discrimination and social protest or movements against some solid waste management project in Sri Lanka. The cultural attitude and psychological perception of dirt are very 
important in solid waste disposal practice of people. The cultural theory of dirt introduced by Marry Douglous is very much applicable and useful in planning socially accepted solid waste management project and community participation in waste management. The unbiased socio-cultural strategies need to focus on ethnicity, livelihood, urban neighborhood, and cultural food practice to minimize the waste generation. The power relation centered around the cultural regimes and urban political ecology are important determinants in this regard. Finally, the gender relationship plays a vital role from waste generation to sustainable management. It does not mean that women must be responsible for controlling and managing the crisis. The grass root social knowledge and community participation are related to gender aspects of the sustainable management of solid waste crisis to a greater extend.

\section{References}

Bandara, N. (2008) Municipal Solid Waste Management: A Sri Lankan Case. University of Sri Jayawardenepura. Department of Forest and Environmental Science.

Beall, J. (2006) Dealing with Dirt and Disorder of Development: managing Rubbish in Urban Pakistan, Oxford Development Studies, 34, (1): 82 -97.

Beck, U. and Beck, E. (2005) Individualization. London: Sage.

Buck, M. N. (1993) Environmental consciousness and urban planning, Hydrabad, Orient Longman.

Burger, P. (1966) The Social Construction of Reality (with Thomas Luckmann), Garden City: Doubleday.

Caron, J. A. and Sheppard, J. A. (1995) The Black and White environmental concern gap: An examination of environmental paradigms. Journal of Environmental Education.

Caron, J. (1989) Environmental Perspectives of Blacks: Acceptance of the New Environmental Paradigm. Journal of Environmental Education, 20: 21-26.

Douglas, M. (1966) Purity and Danger: An Analysis of the Concept of Pollution, Taboo, New York: Roultedge. 
Douglas, M. and Wildavsky, A. (1982) Risk and Culture: Anthropologizing Environmentalism ed; Donald Elliot, 888-898, Yale.

Environmental Protection Agency (2001) Definition of Solid Waste and Hazardous Waste Recycling, Information developed by Booz Allen.

Furedy, C. (1990) Social Aspects of Solid Waste Recovery in Asian Cities, Environmental Sanitation Reviews, No. 30, December, York University, Canada.

Gille, Z. (2007) From the Cult of Waste to the Trash Heap of History: The Politics of Waste in Socialist and Post-socialist Hungary. Bloomington: Indiana University Press.

Gunaruwan, L.T, \& Gunasekara, W.N. (2016) Management of Municipal Solid Waste in Sri Lanka: A comparative appraisal of the economics of composting. NSBM Journal of Management vol 2 No 1 Jan June 2016.

Guan, D., Hubacek, K. and Bavua, A. (2002) Changing Life Styles and Consumption pattern in developing countries, School of Earth and Environment. Leeds.

Hawken, P. (1994) The Ecology of Commerce; a Declaration of Sustainability, Harper Business, New York.

Mahees, M.T.M. (2010) Environmental Movements in Sri Lanka, Germany, VDM Publisher.

Mahees, M.T.M. and Silva, K.T. (2011) Awareness, attitude solid waste generation and water pollution in upper Mahaweli catchment. Dhaka: 3rd International Conference on Water and Flood Management.

Mahees, M.T.M., Sivayoganathan, C., and Basnayaka, B.F.A. (2011) Consumption, solid waste generation, water pollution in River Mahaweli. Kandy: Tropical Agricultural, 22. (3): $239-25$.

Mahees, M.T.M., Sivayoganathan, C., Basnayaka, B.F.A., and Silva, S. (2008) Water Pollution in Pinga Oya: an gender analysis. Proceedings of Water Resources Research in Sri Lanka, University of Peradeniya, $169-177$.

McDougall, M. F., White, P. Frank, M and Hardle, P. (2001) Solid Waste Management: a life circle inventory, Oxford: Blackwell.

Ministry of Mega polish \& Western Province Development (2017) Feasibility Study Report for Municipal Solid Waste Disposal. Colombo.

Morrissey, J. and Manning, R. (2001) Race, Residence and Environmental Concern: New Englanders and the White Mountain National Forest. Human Ecology Review, 7, (1). 
Nagle, J. C. (2009) 'The Idea of Pollution', Law Review, University of California, Davis, 43(1).

NSWMSC (2008) National Solid Waste Management Status Report. 2007. Colombo. NSWMSC

O'Brien, M. (1999) Rubbish-power: towards a sociology of the rubbish society,' pp. 262-277 in J. Heam and S. Roseneil (eds) Consuming Cultures: Power and Resistance. London: Macmillan

Panch, J. (1993) Urban Water Supply: An exploratory study on water supply in Madras, Ahmadabad. Centre for Environmental Urban Planning and Technology.

Pardo, M. (1997) The Waste Society: Some elements for a Social theory of Waste in Modern society, Available on: http://mercedes.pardo @uczm.es

Scanlan, J. (2005) On Garbage, London: Reaktion Books.

Strasser, S. (1992) Waste and Want, Other side of Consumption, Oxford: Berg Publisher.

Sirisena, W. M. (2010) Environmental Sociology, Warakapala, Ariya Publishers (in Sinhala).

Taylor, D. (1989) Blacks and the Environment Towards an explanation of the concern and action gap between blacks and whites. Environment and Behavior, 21, 175-205.

Vineeshiya, M.N. \& Mahees, M.T.M. (2016) Gender Perspective of Solid Waste Management: A case of Balangoda Urban Council. Journal of Built Environment, University of Moratuwa.

Werellagama D.R.I.B. (2000) Collaborative program to prevent pollution of the Upper reaches of Mahaweli River - Sri Lank Department of Civil Engineering, University of Peradeniya, Sri Lanka Friday 28 February 2003.

Wuthnow, R., Hunter, J. D., Bergesen, A., and Kurzweil, E. (1984) Cultural Analysis, London: New York Routledge. 